\title{
The Three-Talk Model: Getting Both Evidence and Preferences into a Pre-Service Teacher Health Workshop
}

\author{
Albert Zeyer ${ }^{1, *(1)}$ and Julia Arnold ${ }^{2}$ (I) \\ 1 Science Teacher Education, University of Teacher Education Lucerne, 6003 Luzerne, Switzerland \\ 2 Center for Science and Technology Didactics (ZNTD), University of Applied Sciences and Arts Northwestern \\ Switzerland, 4132 Muttenz, Switzerland; julia.arnold@fhnw.ch \\ * Correspondence: albert.zeyer@phlu.ch
}

Citation: Zeyer, A.; Arnold, J. The Three-Talk Model: Getting Both Evidence and Preferences into a Pre-Service Teacher Health Workshop. Sustainability 2021, 13, 13937. https:/ / doi.org/10.3390/su132413937

Academic Editor: Graça S. Carvalho

Received: 30 October 2021

Accepted: 10 December 2021

Published: 16 December 2021

Publisher's Note: MDPI stays neutral with regard to jurisdictional claims in published maps and institutional affiliations.

Copyright: (c) 2021 by the authors. Licensee MDPI, Basel, Switzerland. This article is an open access article distributed under the terms and conditions of the Creative Commons Attribution (CC BY) license (https:// creativecommons.org/licenses/by/ $4.0 /)$.

\begin{abstract}
We describe a pre-service teacher workshop about sustainable health decisions in school. This one-week workshop had two goals: to improve the ability of students to cope with health and illness as teachers in daily school life, and to improve scientific literacy in health contexts. In this way, the workshop aimed at creating a situation of mutual benefit between science education and health education, as it is suggested in the new science pedagogy called Science I Environment I Health. To reach this aim, the workshop was structured by the evidence-preference approach and the three-talk model, both originally developed for shared-decision making in medicine. In the evidence-preference approach, the experts (the physician, here the teacher) provide the best evidence available, while the laypersons (the patient, here the teacher students) bring in their preferences and, together with the experts, find their personal standpoint. This process is structured by the three-talk model, which is conceived as a characteristic succession of choice talk, option talk, and decision talk. We describe how the pre-service teacher workshop embraced this new approach, compare it to a scientific literacy point of view, and suggest how it could be applied in many other educational contexts, particularly in many issues of education for sustainability.
\end{abstract}

Keywords: science education; health education; education for sustainability; science literacy; health literacy

\section{Introduction}

During the last decade, Science I Environment I Health, a new pedagogy of science, has been established in the ESERA (European Science Education Research Association) community (e.g., [1]). The basic vision of $\mathrm{S} \mid \mathrm{E} / \mathrm{H}$ is to foster a win-win situation between the three involved educational fields-science education, environmental education, and health education - that had been underexploited so far. Zeyer and Dillon wrote: "The label Science I Environment I Health is not meant to suggest that health and environmental education should be swallowed up by science education. Rather, there is a role for both beyond a reimagined science education. The label highlights a situation of mutual benefit between science education, environmental education, and health education, three educational dimensions that have yet to be established in a transdisciplinary dialogue" [2] (p. 1).

In this paper, we would like to describe such an approach in the special context of a pre-service teacher workshop about health and illness in school. In health contexts, it is important to take into account that health decisions are usually a matter not only of facts but also of value. The term value is used here in the broadest sense, covering moral, social, political, and aesthetical aspects, as well as feminist and religious points of views, i.e., whatever areas are deemed to encompass an evaluative aspect [3]. Roughly speaking, this means dealing correctly with scientific facts without forgetting values-particularly when it comes to decision-making (e.g., [4]). 
The approach that we are going to describe draws from a concept developed in medicine that seeks to consider these two aspects of health decisions-facts and values-in a systematic and consistent way. It has been condensed in the formula of getting both evidence and preferences into health care [5]. We will describe how this approach helped us to structure our workshop and to realize the goals we had with it. We believe that this approach can be adapted to many educational situations at all levels that prepare students for sustainable health decisions.

\section{Health and Illness in School-A Workshop for Pre-Service Teachers at the University of Teacher Education of Lucerne, Switzerland}

The workshop we are going to discuss is offered every year at the University of Teacher Education of Lucerne, Switzerland, to all students during the third semester of their professional education. It is a one-week workshop called "Gesundheit und Krankheit in der Schule" (Health and Illness in School). The students are pre-service teachers for primary school and early secondary school, about 330 in number each year. One of us (AZ) is the head instructor of this workshop and has helped to conceptualize it from its inception. The teaching team consists of a dozen lecturers, all with a background of health or medicine education. We set two goals for this workshop. The first goal was to improve the ability of students to cope with health and medical issues in daily school life. We could call this health literacy in school contexts. Here, we are not only talking about issues like first-aid situations, allergic reactions or poisoning accidents, but also about chronic illnesses in school like diabetes mellitus or epilepsy, and issues of sexuality and sexually transmitted diseases (STDs). A fourth issue that we usually cover is the topic of vaccination.

The second goal of this workshop is to improve scientific literacy in health contexts. At face value, this may be astonishing. However, it had been realized by the university board that most students during their professional education had no contact with natural sciences. Therefore, this week was seen as an opportunity for many of those students to reflect on natural science topics, at least once during their studies. Since most of these students were women, and health topics are known to be motivating science contexts for female students, the second goal was seen as appropriate for this week to create a situation of mutual benefit between science education and health education, according to the goal of the new Science I Environment I Health pedagogy. In paragraph 4, we will come back to the structure of the workshop in more detail.

\section{Science Literacy and the Need for Additional Conceptual Background in the Workshop}

\subsection{The PISA 2006 Framework of Science Literacy}

The full title of this workshop, Health and Disease in School, was often abbreviated to Health Week. It was frequently necessary to remind people that this week was not only about health promotion, but about health and illness in school, and that the second goal of this week was the promotion of scientific literacy in health contexts. Particularly during the first years, the role of science in this week was contested by some lecturers engaged in health promotion, and, eventually, the problem could only be "solved" by replacing some of the lecturers by others that were less ambivalent against "science".

Therefore, it was important to keep in mind what science literacy really is. Figure 1 displays the theoretical framework that was used in the PISA project of 2006. It is very common in science education [6].

The structure of the special week wanted to reflect this framework in order to make sure that the week did in fact promote scientific literacy. As shall be seen in paragraph 4 , the week provided a host of various personal life situations that involved science and technology, mostly biology and medicine. All of them required applying scientific competencies, which is the center of the PISA framework: identify scientific issues, explain phenomena scientifically, and use scientific evidence. In this sense, fostering scientific literacy was truly a core content of this workshop. To involve scientific knowledge and 
discuss attitudes towards science seemed to be a natural part of the week, if only one was careful to keep an eye on it.

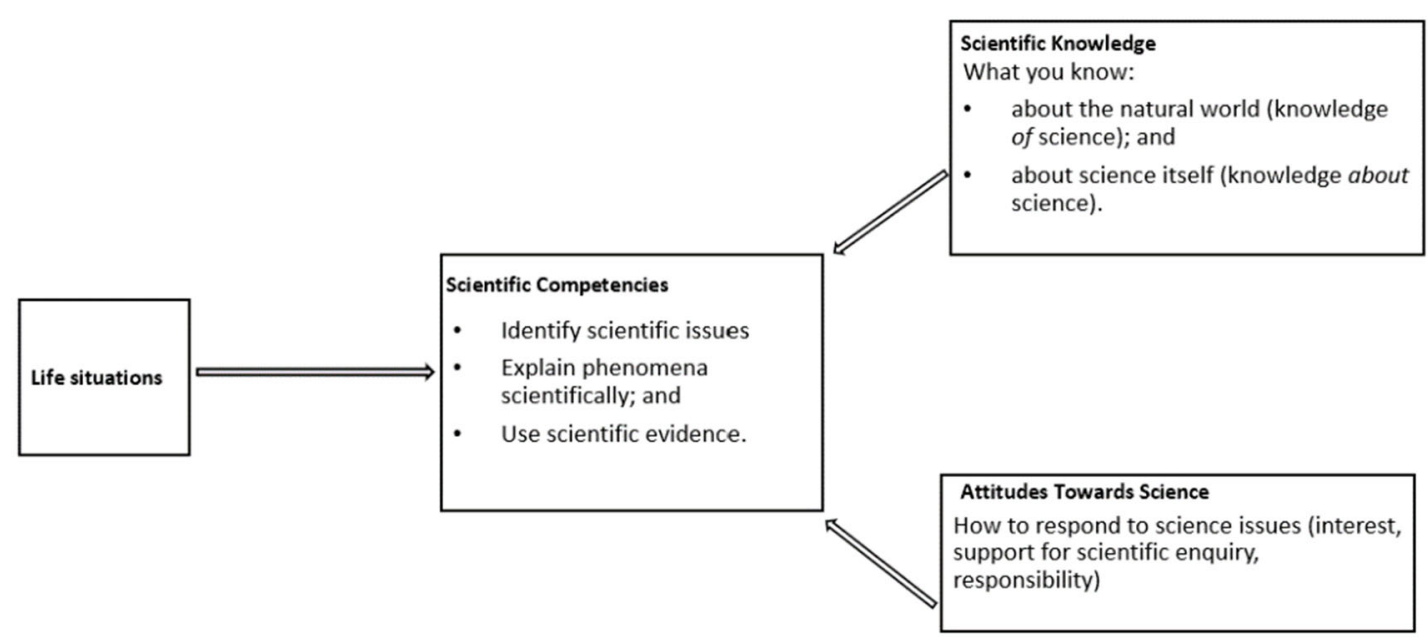

Figure 1. Framework for PISA 2006 science assessment (adapted with permission from Ref. [6]. 2021 Albert Zeyer).

However, as mentioned above, there is more to sustainable health behavior than just applying scientific competencies to health contexts. To illustrate this, consider Figure 2. It displays a framework for health literacy that wants to underline the interplay of facts and values in their broadest sense in health contexts [7]. It shows that to apply scientific competencies is only one aspect of the process. With the construction of a situational model, values come in - through what is called, in the model, self-reflection and cultural background, but also through experiential knowledge, which is contrasted to algorithmic knowledge. The situational construction results in different suggestions for the course of action, which must undergo evaluation, in this model represented by the three aspects of Antonovsky's sense of coherence.

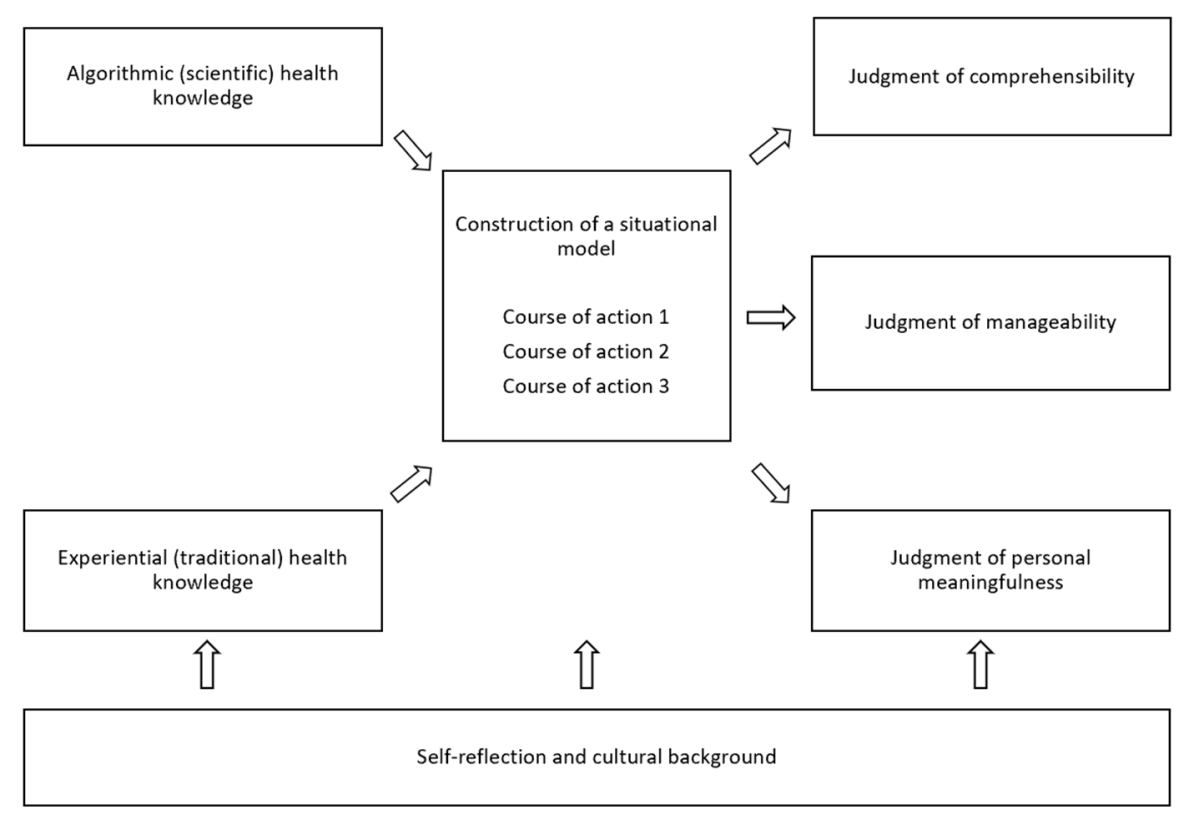

Figure 2. A framework model for health literacy (adapted with permission from Ref. [7] 2021 Albert Zeyer).

The structure of this framework displays the complexity of sustainable health decisions nicely. It makes salient that different options for courses of action are conceived as a result of a constructional process. They do not immediately result from the application 
of scientific knowledge to a "given" situation-as the PISA 2006 framework of science literacy suggests-but need a reflection of preferences. This is exactly what the evidence and preference (E\&P) approach in medicine wants to capture.

\subsection{Evidence and Preference (E\&P) in Medicine}

The E\&P approach in medicine has been developed in the context of shared decisionmaking, today's most popular model in patient-centered medicine [8]. Shared decisionmaking has been defined as an approach where clinicians and patients share the best available evidence when faced with the task of making decisions, and where patients are supported to consider options in order to achieve informed preferences [9]. Patients and doctors are then equal, complementary partners. Patients contribute information about their preferences (i.e., their evaluative perspective) by considering the situation from their subjective point of view. Physicians communicate professional evidence (i.e., the factual perspective) and contribute to an optimal decision-making process by objectively distancing themselves from the clinical situation [10]. Shared decision-making, or participatory decision-making, is increasingly seen as an ideal model for decision-making in the clinical context, but it is not yet standard in medical practice.

In our context of science education, there are three interesting points that may inspire educational situations (e.g., [11]):

- The model emphasizes evidence instead of knowledge. Roughly speaking, knowledge is about truth, while evidence is about facts, i.e., the effectiveness of an intervention in achieving an outcome (e.g., [12]). This is a tribute to the complexity of health and medicine contexts. In complex contexts, because prediction is often flawed, scientific knowledge may suggest measures that do not work under real-world conditions, while, conversely, things may turn out to work that are not backed up by knowledge, or that are only backed up with the benefit of hindsight. For health and medicine clients, however, "what works" is much more important than "what is true".

- The model puts preferences on a level playing field with evidence. Preferences are the totality of what we roughly called values, like the clients' environment, needs, emotions, and fears, as well as the subjective knowledge of their health and disease they bring to the discussion. There is no such thing as "overruling preferences by evidence" [11].

- The model shares responsibilities. The doctor is responsible for knowing the best evidence and communicating it appropriately to the client. Notice that it is not only the doctor's personal evidence that counts, but also the totality of the professionally negotiated evidence, condensed in professional guidelines that the doctor draws from. Usually, these guidelines result from the summary of a systematic and strict review of existing studies done by specialists [12]. The patient is responsible for featuring their value perspective and communicating it to the doctor. Of course, as always in good medical practice, the patient always has the final say.

\subsection{The Three-Talk Model in Medicine}

In the clinical context, a concept exists to systematically bring evidence and preference into a reflective equilibrium. It is called the three-talk model of shared decision-making. There are some different versions of this model. For our purposes, we use here the original version [8] (Table 1).

The three-talk model splits the interaction between doctor and patient into three steps. The first step is called choice talk. Its important role is to emphasize that there is a choice, which is notably determined by the patient's preferences, and that offering choice is not an expression of the doctor's incompetence or weakness.

The second step is called option talk. Here, different therapy options are presented and evidence about the pros and cons of the different options is discussed. 
The third step, the decision talk, focuses on preferences. The patient reflects on what is most important to him or her. Importantly, the decision talk may result in a decision, but also in the deferral of a decision.

Table 1. The three steps of the three-talk model (adapted with permission from Ref. [8] 2021 Albert Zeyer).
Offer choice. Be aware that patients often misconstrue the presentation of choice and think that the clinician is either incompetent or uninformed, or both.
Justify choice. Emphasize: (1) the importance of respecting individual preferences, and (2) the role of uncertainty. Personalizing preferences. Explaining that different issues matter more to some people than to others.
Uncertainty. Patients are often unaware of the extent of uncertainty in medicine: that evidence may be lacking and that individual outcomes are unpredictable at the individual level.
Defer closure. Some patients react by asking clinicians to "tell me what to do..." We suggest deferring closure if this occurs, reassuring that you are willing to support the process.

Step 1: Choice Talk

List options. Make a clear list of the options, as it provides a good structure.

Step 2: Option talk

Describe options. Generate dialogue and explore preferences. Describe the options in practical terms.

Harms and benefits. Being clear about the pros and cons of different options lies at the heart of shared decision-making.

Focus on preferences. Guide the patient to form preferences. Suggested phrases: "From your point of view, what matters most?" Elicit a preference. Be ready with a back-up plan by offering more

Step 3: Decision talk time or being willing to guide the patient, if they indicate that this is their wish.

Moving to a decision. Try checking for the need to either defer a decision or make a decision.

\section{How the E\&P Approach and the Three-Talk Model Connect to the Workshop \\ 4.1. Educational Methods Used in the Workshop}

As has already been said, our idea is that the three-talk model of E\&P not only may find its significance in medicine and shared decision-making but also might be widely applied in various educational health contexts. In this section, we will describe how our pre-service teacher workshop was designed on the basis of this model and has since been successfully implemented for many years.

Basically, we used three educational methods to structure the health week:

1. Autonomous learning sequences. In these sequences, the students read scientific documents in order to improve their scientific knowledge about the issues at stake. For example, they read a short text about diabetes mellitus or epilepsy, or study short passages about the male and the female anatomy to set the scene for further instruction on contraception and STDs.

2. Lectures about health and medical issues in school. These lectures were evidencebased. For example, information was presented on what is known about the incidence of poisoning accidents in children and youths, about the substances that were involved, and about evidence-based first-aid measures that should be taken in case of an incident. A further example was the presentation of evidence about the current STD situation in Switzerland and about the effectiveness of various contraception methods for preventing different STDs. Medical doctors and other health experts gave these lectures.

3. Workshops. In 90-min workshops, the health and medical issues were contextualized for school life. School experts in sex education, for example, presented educational 
methods and discussed practical challenges with the students. A school nurse talked about her experiences with chronic illness in school, like cystic fibrosis, coeliac disease, diabetes, and asthma, and reflected with the students on tasks and challenges for teachers when confronted with chronically ill children in their classes, and the handling of parents, colleagues, and other students.

During the special week, these three educational entities were sequenced in the following way:

The week started by an opening lecture. In this lecture, the framework model for health literacy was presented (Figure 1, above). With the help of this model, many factors were shown to influence the situational construction of a health issue, and scientific knowledge is only one (important) factor in this game. We pointed out that nobody should feel brainwashed or compelled to act in a precisely foreseeable manner, but that our intention was to provide scientific and experiential knowledge as much as possible and help students to construct their own situational model for each issue, based on their self-reflection and their cultural background, and to start evaluating various courses of action. Moreover, as we pointed out, this is an ongoing process undertaken during their whole professional lifetime as teachers. Then, in a discursive lecture setting, this process was illustrated and developed together with the students for health contexts like adipositas or ADHS.

After this, the design of the week was explained, which consisted of ongoing lectures, alongside time for autonomous learning and workshops that were organized in a very structured manner. Ideally, there was a fixed sequence of educational elements. For example, before students were asked to discuss the management of tick protection in school classes, they would have learned about ticks and the diseases spread by these parasites in autonomous learning sequences and then have heard about evidence of infection and treatment. Take another example: students would learn about the human papilloma virus and cervical cancer in an autonomous learning sequence, then learn about evidence concerning HPV vaccination, and, finally, reflect on their role as teachers when the local health care service provided vaccinations to the students.

Of course, for organizational reasons, it was not always possible to keep to this optimal order; in principle, however, this was the basic idea of the week's structure. At the end of the course, the students had to pass an exam that tested their bio-medical knowledge and evidence about the covered areas. The workshops were not tested, but attendance was monitored.

\subsection{How Can the Three-Talk Model Be Used to Structure the Workshop?}

We said that the three-talk model approach to E\&P in medicine can only be literally transferred to educational situations in rare occasions, but that it can be a helpful inspiration to structure educational sequences. In this section, we would like to illustrate this statement with the previous workshop examples.

\subsubsection{Step 1: Choice Talk}

The first lecture is inspired by the choice talk. The presentation of the framework model of health literacy signifies that there is no shortcut between evidence and preference, and that the aim of this week is not to condition students to standard reflexes when dealing with health contexts in school. On the contrary, it encourages students to carefully draw from the various sources of knowledge that are offered during the week, and to make up their own minds and start their own life-long situational construction process, that may lead to adequate and appropriate action. In fact, this opening sequence and the presentation of the framework proved to be very helpful as a mind opener and to prevent the skeptical withdrawal of students during the week. In the first years, when this opening concept had not yet been introduced, we were frequently confronted with the problem that students feared "brainwashing". Particularly when it came to controversial issues like ADHD, contraception, or the handling of chronic diseases in school, students seemingly relaxed after we had started to use the framework. In Switzerland, many cultural differences 
and societal controversies are present concerning alternative methods in medicine, sex education, or teachers' responsibilities for students, and the pre-service teachers quickly feared getting involved into the discussions, or being expected to act against their personal beliefs. The opening lecture calmed these suspicions from the outset.

\subsubsection{Step 2: Options Talk}

The second talk, the options talk, was mirrored by the lectures. The lecturers presented evidence-based options in school health contexts and discussed the pros and cons. For example, in a lecture titled "everyday medicine in school," the treatment of fever in school camps was thematized. The lecturer discussed evidence-based the pros and cons of remedies like Aspirin or Paracetamol, and of physical measures like adequate hydration. This discussion also included legal aspects and urgency issues. Another example was the topic of sun protection, in which the lecturer presented the evidence-based role of the time of day, different sun creams, and textiles.

\subsubsection{Step 3: Decision Talk}

Almost every topic discussed in this week offers different evidence-based options for action. It was in the workshop that these options were recapitulated and discussed. In this way, the workshops reflected the intentions of the decision talk. For example, in a workshop about chronic illness in school, various options of blood glucose control were discussed. Many students were concerned about insulin injections and first aid in cases of hypoglycemia. An experienced school nurse explained how she handled such cases, and what a teacher can do and where the limits of teachers' action lie, including the legal limits. In any case, first-aid situations were an important concern for the students, such as in the case of allergic reactions, asthma, or physical injuries. One workshop was called "When should I call the doctor?".

A particularly important aspect of the decision process initiated in these workshops was that a specific decision was not pushed. Of course, the situation of the students in this workshop was different from the situation of patients in the doctor's surgery. The presented contexts were only fictive (at least at that time). The workshop lecturers may have presented their own experiences and actions, but the natural way of closing such a workshop was to defer reaching a decision and to point out how important it was that the students had started in this week their personal decision-making processes and would not have to start from scratch. They were now, at least partially, prepared for similar situations they might face during their career as teachers.

\subsection{A Comparison of Scientific Literacy and the Evidence and Preference Approach}

The PISA 2006 concept of scientific literacy seems to be very close to the evidence part of the E\&P approach, and particularly to the options talk in the three-talk model. However, there is an important difference. In the scientific literacy approach, the actors are the students, or, generally the scientifically literate persons. It is they who perform the scientific competencies, i.e., identify the science in health contexts, explain phenomena scientifically, and use scientific evidence for decision-making.

In shared decision-making, it is the expert who is responsible for this part. The reason is obvious. As has been pointed out in our introduction, health contexts are usually complex, and the successful performance of the scientific competencies is far beyond what a single person can handle, be they an expert or a layperson. In fact, in this special week, how could any student be expected to act autonomously and in a scientifically literate way in such diverse health contexts as asthma, allergies, vaccination, first aid, and STDs? How could any teacher-to expand the perspective-expect to behave in a scientifically literate way from scratch in contexts like diabetes in school, concussion, occasional poisoning, etc. Nobody would. In fact, nobody would even like them to do so because the risk of failure would be so great and the consequences sometimes devastating. 
Equally, we would not like the lecturers and experts in this special week to do so. In complex health and medical contexts, the application of scientific competencies, including the generation and the use of evidence, is a matter of an excessively sophisticated process of scientific and social negotiation. It is never the result of a single person's efforts, no matter how accomplished they may be. Usually, this negotiation of evidence results in commonly accepted guidelines, which are then presented and used by the experts, be they medical doctors, the presenters in our workshops and lectures, or anyone else. If a lecturer in this special week were to say "The guidelines say that after a concussion, children should be monitored for $24 \mathrm{~h}$, but I do not recommend that," we would consider them simply mad. This would be a severe violation of the core rules of evidence-based practice.

In the present case of school health contexts, evidence-based guidelines clearly demark, together with legal considerations, options and limits of teacher intervention. Yet within these boundaries, there is always space for different shades of decision-making, that clearly depend on each teacher's preferences. But apart from the teachers, the parents, the children themselves, their peers, and other teachers of the team will also be involved and have their respective preferences. Take for example the management of chronic diseases like asthma, diabetes, or even cystic fibrosis or chronic arthritis. Evidence-based guidelines today mostly give clear advice, but how to implement this advice within a complex school life is quite another thing. What if students with asthma do not want to keep their first-aid remedy on them? What if parents with an epileptic child do not consent for the information about their child's illness to be shared with other staff? What if the teacher fears legal problems when taking a child with diabetes on a school camp? How can a child with coeliac disease have a safe and healthy diet without hampering their social integration?

All these questions need an E\&P approach, and they show that the preference side is not just a nuisance, but often indicates important aspects to keep in mind. Even if the guidelines are completely clear, and even if a teacher may make use of professional help (a school nurse, for example, which in many parts of Switzerland is still by no means the norm in schools), there are always situations of decision-making where preferences point to important aspects for consideration. Yes, adolescents often fear being teased because of their health problems. Yes, epilepsy may result in a child's stigmatization. Yes, an unintended side-effect of a teacher's intervention may cause legal problems. In the week's workshops, all these subjective aspects of decision-making were thematized. If both the evaluative aspects of preference and the factual aspects of evidence are seriously considered, better and more adequate decision-making and better outcomes are likely to be achieved.

The second difference between scientific literacy and an E\&P approach results from the subjectivity of health contexts, as pointed out in our introduction. We explained that, together with the limits of prediction in complexity, this gives preference an essential role. Notice that in science literacy, the only factor that could be subsumed under "preferences" is the factor "attitudes towards science". Of course, this is an important aspect of "preferences", but by no means the only one. For example, in the case of the HPV vaccination, attitudes towards science play indeed an important role. However, we found that other preferences were at least as important for the decision for HPV vaccination, for example, the preference to regularly go to the gynecologist's and have a cancer smear, or the anxiety that letting kids have the vaccination would signal to them sexually liberal attitudes.

Of course, the PISA 2006 framework of scientific literacy suggests that improving the attitudes towards science would help improve scientific literacy, and this was exactly what was intended in the workshop. Generally, it was hoped that the opportunity to see the importance of science for health decisions would help students to develop a positive attitude towards science, particularly students who had no opportunity to get acquainted with science during their studies. Yet, conversely, it was also assumed that the use of evidence would have an impact on preferences. For example, it was hoped that the evidence of the vaccination's preventive advantage over the ex post detection of a cancer smear would modify students' preferences (which it actually did, at least for some). 
This process is not modeled in scientific literacy, simply because an autonomous role of preferences is not assumed. Indirectly, it is suggested that an optimal use of evidence results in one solution, that is objectively "the best" - a well-known variant of the naturalist fallacy that is rather common among scientists and science educators. As we have seen, this is seldomly the case in complex health contexts.

\subsection{The Role of Knowledge and Fake Knowledge}

Finally, it is interesting to see the role of knowledge in this framework and to compare it with our experiences in the special week. Scientific literacy often sees scientific knowledge as the core of science education. If students acquire correct scientific knowledge, the basic (and often undeclared) assumption is that they will apply it spontaneously and autonomously in health contexts, and thus they will make rational health decisions. The better the knowledge, the better the decisions. Sometimes this is called vision I of scientific literacy.

Yet scientific literacy as represented in the PISA framework of Figure 2 (sometimes also called vision II of scientific literacy) conceptualizes the role of knowledge differently. Here, scientific knowledge is only influencing the way students deal with scientific competences, particularly how they use evidence. Scientific knowledge is on the same level, and has a comparable influence, as the attitudes towards science. Scientific knowledge is a helping bystander to the scientific competencies-not more, but also not less.

In the special week, the role of knowledge was closer to vision II than to vision I. For example, the issue of the HPV vaccination was not thematized mainly through a knowledge approach. In one of the sequences of autonomous learning, the students learned about the HP virus, its role in the pathogenesis of cervical cancer, and the basic mechanism of vaccination. Yet it was not assumed based on this knowledge that student teachers would autonomously draw "rational" conclusions about the HPV vaccination and its importance for adolescents. This argumentation was part of a lecture, and the knowledge acquired before was intended to help students to understand it, and particularly the evidence for vaccinating the children of their future school classes.

Does better (scientific) knowledge result in better decisions? Vision I is here straightforward and concludes that "fake knowledge" must be replaced by scientifically correct knowledge, and that this will directly lead to scientifically correct decisions. What is more, in this vision the decision with the best evidence is considered the "right" decision.

Vision II is more cautious, as it conceives the impact of knowledge on decision-making less directly. Here, knowledge is considered to open the mind for a better use and a better understanding of the evidence. Naturally, however, it would not question the importance of correct scientific knowledge and the problematic role of "fake knowledge". Nevertheless, in vision II a decision in favor of a choice less favored by science or a deferral of decision would also be accepted. And while in vision I the decision and the correct reproduction of scientific knowledge would be tested in terms of learning assessment, in version II the reflectiveness of the decision would be checked with the inclusion of knowledge and attitudes (or evidence and preference).

In our special week, one assumption that may be qualified as "fake knowledge", and which was rather common among our students, was that the HPV vaccination was based on an attenuated HP virus and could "re-mutate" back to the wild form. We could show that explicitly bringing up this misinformation and correcting it during the lecture about vaccination had a certain impact. It did not massively change students' decision-making, but it made them generally more open towards the benefits of the HPV vaccination.

\section{The E\&P Approach and the Three-Talk Model in School}

So far, we have demonstrated how an E\&P approach in a special week on health issues at a university of teacher education supports the promotion of scientific literacy in health contexts. We have also shown that such an E\&P approach has some advantages compared to a purely literacy-oriented approach, and that the three-talk model is a good 
way to structure the week appropriately. In this section, we would like to describe how our insights could be applied to the concept for generally improving scientific literacy in heath contexts at school.

The described special week dedicated a whole week to health contexts in school, and it was aimed at improving the health literacy and scientific literacy of future primary and lower secondary teachers. This situation is special, and we are generally interested in the question of raising scientific literacy in the health contexts of students at any school level.

First, it must be said that it is unnecessary to focus so intensely on health contexts in normal school situations. For example, as Bybee [13] points out, in science education, health contexts need not become so dominant in order to achieve our goal. In normal school life, it is enough to put them forward every now and then in the classroom, before turning back to other, non-health-related topics. This can be done not only in the science classroom, but also in any teaching situation at any school level.

When proceeding in this casual, unspectacular way, both the E\&P approach and the three-talk model can be helpful either as a full concept or by focusing on parts of it in various combinations. In Figure 3, we present a flow diagram that represents a full concept for the teaching process that is inspired from what has been said.

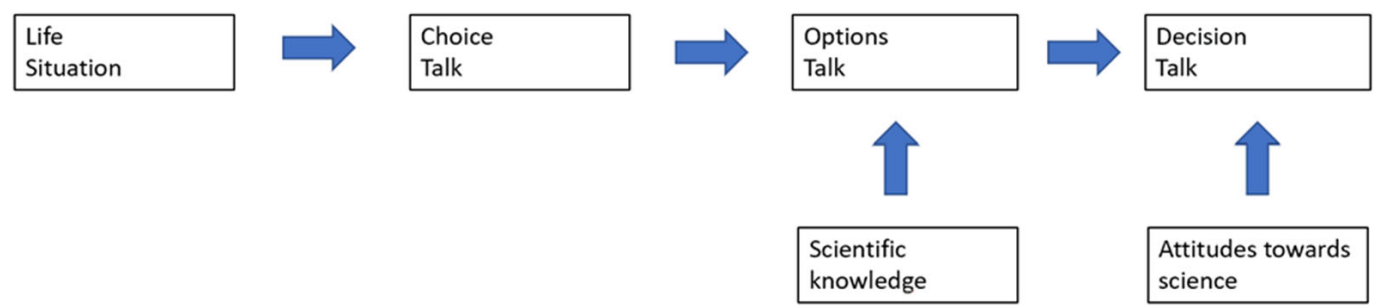

Figure 3. A full-blown expansion of the three-talk model that could structure a lesson, a sequence of lessons, or even, as we have seen, a special week.

\subsection{An Example of a Full-Blown Expansion of the Three-Talk Model}

Here is an example that one of us (AZ) has used in courses for science teacher students. The biology of the human eye is an excellent opportunity to integrate physics into biological reasoning. Ray optics may well explain how myopia (nearsightedness) can develop and how it may be corrected by glasses. This is the standard content of most science curricula in school. However, it is seldom mentioned that other approaches to the therapy of myopia also exist, most importantly laser eye therapy and, less evidence-based, eye relaxation exercises. The example makes use of this. Thus, the life situation at stake is short-sightedness and the options of therapy. It is of interest for most students, particularly for those who suffer from myopia themselves. The full-blown three-talk model expansion starts by a traditional introduction to the biology of the human eye and its optics. In the same, classical way, the function of glasses and the correction of myopia by dispersive lenses are introduced. Then, the teacher asks the teacher students if they had personal experience with other ways of treating myopia. In most cases, all three options above would be presented, and a discussion would start about the pros and cons of the three methods.

For the teacher, this was the starting point for the choice talk. He would point out the uncertainty in medicine, that evidence was partly lacking, and that it would be interesting to give all three treatments a fair chance. As for many patients in the clinical setting, for many of these teacher students, this was an unfamiliar situation, because they are used to expecting definitive answers from science and experts. Deferring closure is an important task for the teacher at this moment, because, as patients, many students simply want to know which method is considered the best.

In the next sequence of lessons, the students were offered the opportunity to, in a problem-based-learning approach, find out more about the three therapies. The teacher supports this process individually, offers dialogue, and helps to explore the preferences. 
At this stage, it is not easy for the students to describe the three options in practical terms. Normally, what interests them most is the pros and cons, and the harms and benefits of the different treatments of myopia.

As a conclusion of the three-talk approach in this example, the students were called together for the decision talk. Here, everybody was invited to present their preferences, which could also mean that they deferred to decide for one approach. It was important that the teacher avoided to interpret a deferral as a defeat, pointing out that this uncertainty is typical for complex questions of sustainability, and that often a decision has to be made in view of many unknowns.

This result stands in a telling contrast to the PISA 2006 framework model, which seems to suggest that using scientific knowledge to apply scientific competencies normally results in a rational choice of the best treatment. In this example, all three therapeutic options can be explained by scientific reasoning, but not all three are fully evidence-based. Nevertheless, scientific knowledge plays an important role for structuring the options talk in a clear way. In the same way, the PISA 2006 framework model suggests that positive attitudes towards science are a key for successfully applying scientific key competencies to health contexts. This is still true in this example, but obviously attitudes towards science play an ambiguous role in all three treatments of myopia, depending on many other points of view, as indicated in Figure 2.

\subsection{Variants and Shortcuts}

This was an example of a full-blown expansion of the three-talk model. This ambitious setting needs much time and is not always affordable in everyday teaching. However, it is a strength of the model that it allows for many variants and shortcuts. Any life situation that involves health issues may lead to, for example, only a short teaching and learning session in the form of a choice talk. In this session, with the help of the teacher, students could reflect on the fact that one always has a choice in complex health situations-these are the same reflections on complexity and subjectivity in health situations that we have presented in our own introduction. In addition, an isolated options talk could be helpful. In this case, the evidence would be presented, and scientific knowledge would be acquired by the students in order to understand the presented evidence. As in medicine, some tentative reflection on personal preference could be included in such a session.

We are not sure if an isolated decision talk would make sense in school. In any case, it could include students' reflections about their attitudes towards science and the impact of attitudes on the decision-making process. It would also be important to point out that a final decision should never be forced, and decisions can always be deferred. Moreover, it often makes sense to delay deciding. In our experience, it is always hard for students to resist the temptation of forcing themselves or others to decide, and particularly to impose one's own way on others. Of course, teachers are not immune to this temptation. Particularly in health issues, teachers tend to finish a lesson by telling the students "how it is in reality" and to impose on them their own conclusions in the sense of the naturalist fallacy. One of the most important messages that can come through in a decision talk lesson is that there is no shortcut between evidence and preference. That is, based on the same evidence, different people often come to different conclusions, and lessons can and should be finished without a consensus among the involved people, be they students, teachers, or both.

\section{Concluding Remarks}

In this paper, we presented the E\&P approach and an exemplary application in teacher education as well as ideas for its use in schools. In this last section, we would like to conclude with some more general thoughts on the use of the E\&P approach in teachinglearning situations.

Imagine a teaching-learning situation that is based on the three-talk model. The students are then in the role of the future patients, so to speak. While navigating the 
three-talk model, they deal with questions of uncertainty, formulate preferences, and try to reach a personal decision by combining evidence and preference. By doing so, they build up and practice their basic scientific knowledge, their knowledge of the scientific method, and an understanding of uncertainty, probability, etc., i.e., they acquire scientific literacy [13]. However, and this is the important difference, their purpose is not to generate and assess evidence, but to understand and bring it into relation with the preference point of view. They do not apply evidence (this is the role of the expert), but they interpret it. This is in line with the recently started discussion about the epistemic dependence of laypeople. It questions the ideal of a middle-ground stance between believing whatever scientific experts say and believing nothing [14]. This goal seems to be unrealistic, not because non-scientists do not have the ability to be intellectually independent, but because such independence is embedded in judgements of trust rather than one's own full understanding of a phenomenon [15].

Instead of promoting epistemic independence, in our concept, the role of the teacher is to find learning opportunities and to create situations in which the three-talk model can be practiced. This also means that the teacher must slip into the role of the expert (as a proxy, so to speak, for the medical professional) in this setting. This may be a challenge, as, in contrast to the physician, the teacher usually does not have guidelines available that are developed by a medical community. The teachers themselves would have to research evidence and prepare it for the learners, a challenge that in medicine has already turned out to be normally unmanageable for general practitioners. One way to solve this problem could be to develop material packages and make them available to the teachers.

We are well aware that this approach raises the delicate question of what "good" evidence is and how we find it. It is precisely one of the basic assumptions of the three-talk model that in the given situation, there is a consensus among experts about evidence. That evidence is often inconsistent and has to be sought and evaluated on a daily basis is another issue. However, evidence and expertise have to be assessed regardless of whether a teacher must prepare evidence for a three-talk lesson or whether learners have to choose the experts they want to trust, or if they both have to deal with evidence for everyday decisions. It is important to ask questions such as: What counts as evidence? How do I recognize trustworthy sources? When should I question sources? How do I deal with contradictory statements? In other words, reflection and critical thinking play a major role. Scientific literacy is important for this and understanding the nature of science becomes more relevant compared to content knowledge. Furthermore, it is important to reflect one's own preferences and their impact on the decision-making process, and also to be aware of the preferences of other people. Again, the three-talk-model can serve for structuring such lessons, and for giving reflection and critical thinking more space in science teaching (e.g., [16]).

In the present paper, the focus is on health issues and the role of science and scientific literacy in health contexts. However, we believe the E\&P approach can be used in any context of socio-scientific issues, issues that involve not only purely scientific problems, but also more generally complex problems that include personal, social, and contextual aspects, like environmental contexts, contexts of biotechnology, and generally contexts of sustainability. For any of these and other complex problems, bringing the E\&P approach and the three-talk model into classroom practice by elaborating concepts, testing them, and accompanying them with science education research is a task with much promise for students and teachers alike.

Author Contributions: Writing—original draft, A.Z.; writing—review and editing, J.A. Both authors have read and agreed to the published version of the manuscript.

Funding: This research received no external funding.

Institutional Review Board Statement: Not applicable.

Informed Consent Statement: Not applicable. 
Conflicts of Interest: The authors declare no conflict of interest.

\section{References}

1. Zeyer, A.; Dillon, J. Science I Environment I Health-The Emergence of a New Pedagogy of Complex Living Systems. Discip. Interdiscip. Sci. Educ. Res. 2019, 1, 9. [CrossRef]

2. Zeyer, A.; Dillon, J. Science I Environment I Health-Towards a reconceptualization of three critical and inter-linked areas of education. Int. J. Sci. Educ. 2014, 36, 1409-1411. [CrossRef]

3. Schroeder, M. Value theory. In The Stanford Encyclopedia of Philosophy; Zalta, E.N., Ed.; 2021. Available online: https://plato. stanford.edu/archives/fall2021/entries/value-theory/ (accessed on 30 October 2021).

4. Arnold, J.C. An integrated model of decision-making in health contexts: The role of science education in health education. Int. J. Sci. Educ. 2018, 40, 519-537. [CrossRef]

5. Barratt, A. Evidence Based Medicine and Shared Decision Making: The challenge of getting both evidence and preferences into health care. Patient Educ. Couns. 2008, 73, 407-412. [CrossRef] [PubMed]

6. Zeyer, A. A Win-Win Situation for Health and Science Education: Seeing through the Lens of a New Framework Model of Health Literacy. In Science | Environment | Health. Towards a Renewed Pedagogy for Science Education; Zeyer, A., Kyburz-Graber, R., Eds.; Springer: Dordrecht, Germany, 2012; pp. 147-173.

7. Elwyn, G.; Durand, M.; Song, J.; Aarts, J.; Barr, P.J.; Berger, Z.; Cochran, N.; Frosch, D.; Galasiski, D.; Gulbrandsen, P.; et al. A Three-Talk Model for Shared Decision Making: Multistage Consultation Process. BMJ 2017, 359, i4891. [CrossRef] [PubMed]

8. Elwyn, G.; Frosch, D.; Thomson, R.; Joseph-Williams, N.; Lloyd, A.; Kinnersley, P.; Cording, E.; Tomson, D.; Dodd, C.; Rollnick, S.; et al. Shared Decision Making: A Model for Clinical Practice. J. Gen. Intern. Med. 2012, 27, 1361-1367. [CrossRef] [PubMed]

9. Elwyn, G.; Laitner, S.; Coulter, A.; Walker, E.; Watson, P.; Thomson, R. Implementing Shared Decision Making in the NHS. BMJ 2010, 341, c5146. [CrossRef] [PubMed]

10. Gerber, M.; Kraft, E. Shared Decision Making-Arzt Und Patient Entscheiden Gemeinsam. Schweiz. Arzteztg. 2014, 95, 1883-1889.

11. Zeyer, A. Coping with structural uncertainty in complex living systems. In Science | Environment | Health-Towards a Science Pedagogy of Complex Living Systems; Zeyer, A., Kyburz-Graber, R., Eds.; Springer: Berlin/Heidelberg, Germany, 2021; in print.

12. Toon, P. Theories of Knowledge What is evidence? Lond. J. Prim. Care 2014, 6, 95-97. [CrossRef] [PubMed]

13. Bybee, R. Scientific literacy in environmental and health education. In Science I Environment I Health. Towards a Renewed Pedagogy for Science Education; Zeyer, A., Kyburz-Graber, R., Eds.; Springer: Dordrecht, Germany, 2012; pp. $49-67$.

14. Sharon, A.J.; Baram-Tsabari, A. Can science literacy help individuals identify misinformation in everyday life? Sci. Educ. 2020, 104, 873-894. [CrossRef]

15. Fooladi, E.C. Between Education and Opinion-Making: Dialogue between Didactic/Didaktik Models from Science Education and Science Communication in the Times of a Pandemic. Sci. Educ. 2020, 29, 1117-1138. [CrossRef] [PubMed]

16. Arnold, J.; Bauer, D. The Role of Science Education in Decision Making Concerning Health and Environmental Issues. In Science | Environment | Health-Towards a New Science Pedagogy of Complex Living Systems; Zeyer, A., Kyburz-Graber, R., Eds.; Springer: Dordrecht, Germany, 2021; in print. 